\title{
My Skin - a self-questionnaire for assessment of the emotional-cognitive representation of skin
}

\section{BACKGROUND}

The aims of this paper are: 1 ) to present the My Skin questionnaire, 2) to report the preliminary results of a study on the emotional-cognitive skin representation, and 3) to encourage dermatologists and other specialists to use the My Skin questionnaire in their research. The inspiration for a new tool measuring the emotional and cognitive representation of skin was the psychological conception of the 'skin ego'.

\section{PARTICIPANTS AND PROCEDURE}

My Skin, a self-questionnaire (MSQ), was used to measure the emotional and cognitive representation of an individual's skin. It consists of two main scales: satisfaction with the skin condition $(\mathrm{AB})$ and awareness of the biopsychosocial functions of the skin (C). The Body Esteem Scale, Body Self Questionnaire and Self-Esteem Scale were used to validate the MSQ. The participants were: healthy individuals $(n=343)$ and dermatology patients (psoriasis, vitiligo, juvenile acne, $n=84$ ).

\section{RESULTS}

The psychometric parameters are presented in this article. The internal consistency reliabilities for subscales are in the range of .75 and .95. This article also presents preliminary basic statistics for the skin representation of dermatology patients and healthy people.

\section{CONCLUSIONS}

My Skin questionnaire is a valid tool for assessing cognitive and emotional representation of skin and may be used in psychodermatology and esthetic dermatology to assess satisfaction with and awareness of skin.

\section{KEY WORDS}

psychodermatology; measurement; skin representation; My Skin questionnaire

ORgANIZATION - 1: Department of Clinical and Health Psychology, Faculty in Sopot, SWPS University of Social Sciences and Humanities, Sopot, Poland · 2: Positive Psychology Center, University of Pennsylvania, Philadelphia, PA, USA . 3: Department of Dermatology, Sexually Transmitted Diseases and Immunodermatology of the Nicolaus Copernicus University, Collegium Medicum in Bydgoszcz, Bydgoszcz, Poland

AUthors' Contributions - A: Study design - B: Data collection - C: Statistical analysis - D: Data interpretation .

E: Manuscript preparation · F: Literature search · G: Funds collection

Corresponding Author - Marlena M. Kossakowska, Ph.D., Department of Clinical and Health Psychology,

Faculty in Sopot, SWPS University of Social Sciences and Humanities, 16/20 Polna Str., 81-745 Sopot, Poland,

e-mail: mkossakowska@swps.edu.pl

TO CITE THIS ARTICLE - Kossakowska, M. M., \& Cieścińska, C. (2016). My Skin - a self-questionnaire for assessment of the emotional-cognitive representation of skin. Health Psychology Report, 4(3), 272-280.

doi: $10.5114 /$ hpr.2016.57692 


\section{BACKGROUND}

Human skin has various roles in biological, psychological, and social life. Skin performs the physiological functions of protection, sensation, thermoregulation (by means of evaporation), absorption, water resistance, and finally, storage and synthesis. The psychological functions of skin, meanwhile, are not as well known in medicine. A person gains a unique and inimitable identity thanks to the appearance of his/her skin. For instance, one way in which people differ from one another is in their facial skin. People therefore recognize each other through visible aspects of facial skin. These, however, are merely examples of some of the psychological functions of skin, that is its role in identity (Anzieu, 1989).

Skin is also a very important tool in social communication. People express gender, race and even their mood or health condition in non-verbal communication via the skin. A poor skin condition can lead to social stigmatization of dermatological patients (Kent, 2005). They are sometimes perceived as worse people with a serious infectious disease, and stigmatization results in many psychological and social consequences for chronically ill patients with dermatoses (Ginsburg \& Link, 1989; Kent, 1999; Magin, Adams, Heading, Pond, \& Smith, 2009; Kimball, Jacobson, Weiss, Vreeland, \& Wu, 2005). People with poor skin condition, especially with psoriasis and vitiligo, are characterized, for example, by lower self-esteem, avoidance of a social life, decreased sexuality (Magin et al., 2009) and a lower quality of life (Kimball et al., 2005). These aspects of chronic dermatoses can lead to psychological sequelae (e.g. depression and anxiety), which can maintain or even cause a deterioration in symptoms (Ginsburg \& Link, 1989; Gupta, 2005).

The body is a very important background for the body self creation, which in turn is, primarily, a crucial part of the self - one of the main psychological constructs describing identity. While there are numerous studies on the self and body self, research on the skin ego is still sparse (Anzieu, 1989).

The skin ego is defined as the generalized emotional and cognitive representation of the skin. The concept of the skin ego refers to a part of the physical self: the cognitive and emotional representation of skin, and also the understanding of its physiological, psychological, and social functions. It is formed over the duration a life span, in a developmental process from childhood to adulthood. According to Anzieu (1989), the skin ego is a theoretical psychological construct containing the subjective perception and experience of skin as a very significant organ of a body, which is directly related to the self. The psychological concept of the skin ego assumes that human identity is developed throughout a life span and thanks to that a person is aware not only of physiological but also of psychological and social functions of skin.

It is very difficult to assess the skin ego, so we decided to construct a tool for measuring the psychological (emotional and cognitive) representation of skin. We assumed that if the body esteem contributes to self-esteem, which regulates human behavior (Rosenberg, 1979), skin representation and skin esteem in particular can also be important for people's activity regulation.

\section{PARTICIPANTS AND PROCEDURE}

My Skin

Questionnaire
Scale development. The My Skin questionnaire (MSQ) was created to measure the subjective emotional and cognitive representation of the skin in terms of two aspects: satisfaction with particular parts of one's body and awareness of skin functions. It was constructed based on the American Psychology Association's standards for psychological tests (APA, 1999). The survey items (initially 63 items) were generated by dermatologists, psychologists, dermatology patients and beauty parlors clients (Kossakowska, 2011). The final factor analysis eliminated some items and revealed four factors for the $\mathrm{AB}$ scale, which concern satisfaction with the skin condition, and three factors for the $\mathrm{C}$ scale, measuring awareness of skin functions (see below).

The English translation of the MSQ was prepared for use in English-speaking countries (United Kingdom, United States of America, etc.). The methodology began with two independent forward translations into the target language, first by two independent bilingual experts, and finally by five independent native speakers (three Americans and two Britons), who checked the preliminary versions. Bilingual translators were professionals - one psychologist and one medical doctor - whose task involved ensuring accuracy of terminology. Native speakers were mostly regular people (four persons) and one was a medical doctor. The final version of the English translation was completed by a native speaker who was a psychologist. The English version of the MSQ is presented in the Appendix.

Other measurements. To assess the validity of the MSQ the subjects were examined with the following three tools. The first was the Body Self Questionnaire by Mirucka (2005), which measured females' body self. It consists of four subscales: 1) acceptance of one's body, 2) disclosure of femininity, 3) experience of intimate relations with persons of the opposite sex, and 4) relations towards eating and body weight. The second questionnaire was the Body Esteem Scale (Franzoi \& Shields, 1984; Franzoi \& Herzog, 1986, see also: Lipowska \& Lipowski, 2013), which assesses satisfaction with one's body. It consists of three subscales (separately for females and males): 1) sexual/physical attractiveness, 2) weight concern/upper 
body strength and 3) physical condition. The third measurement was the Self-Esteem Scale (Rosenberg, 1965), a tool which measures global individual self-worth.

Participants. The final factor analysis was conducted on 343 healthy people aged 19-48 (198 women and

Table 1

Factor analysis for part AB of My Skin questionnaire, $n=343$

Marlena M.
Kossakowska,
Czanita

Cieścińska

\begin{tabular}{cccc}
\hline Factor 1 & Factor 2 & Factor 3 & Factor 4 \\
FACE & UPPER & LOWER & ASPECTS \\
\hline
\end{tabular}

\begin{tabular}{rrrrr}
\hline AB I: & & & & \\
AB1 & .81 & -.02 & -.02 & .11 \\
AB2 & .97 & .10 & .09 & .05 \\
AB3 & .97 & .10 & .08 & .05 \\
AB4 & .97 & .10 & .10 & .04
\end{tabular}

AB II:

$\begin{array}{lrrrr}\text { AB5 } & .04 & .72 & .29 & .11 \\ \text { AB6 } & .04 & .80 & .12 & .14 \\ \text { AB7 } & .07 & .75 & .21 & .15 \\ \text { AB8 } & .06 & .48 & .13 & .38 \\ \text { AB9 } & .06 & .56 & .12 & .44 \\ \text { AB10 } & .06 & .43 & .09 & .66 \\ \text { AB11 } & .06 & .44 & .17 & .65 \\ \text { AB12 } & .04 & .41 & .34 & .60 \\ \text { AB13 } & .04 & .33 & .26 & .59 \\ \text { AB14 } & .05 & .16 & .65 & .29 \\ \text { AB15 } & .04 & .42 & .35 & .25\end{array}$

AB III:

$\begin{array}{lrrrr}\text { AB16 } & .10 & .38 & .33 & .1 \\ \text { AB17 } & .06 & .45 & .43 & .36 \\ \text { AB18 } & .08 & .14 & .74 & .2 \\ \text { AB19 } & .03 & .12 & .80 & .25 \\ \text { AB20 } & .05 & .14 & .80 & .30 \\ \text { AB21 } & .06 & .30 & .63 & .2 \\ \text { AB22 } & .04 & .29 & .77 & .08\end{array}$

AB IV:

\begin{tabular}{lllll} 
AB23 & .01 & .24 & .50 & .33 \\
AB24 & .04 & .28 & .37 & .56 \\
AB25 & .05 & .38 & .28 & .54 \\
AB26 & .06 & .04 & .17 & .68 \\
AB27 & .04 & .02 & .30 & .59 \\
AB28 & .08 & .06 & .36 & .67 \\
\hline
\end{tabular}

145 men). The concurrent validity study was conducted on 105 healthy individuals: 73 women aged 19-48 $(M=26.38)$ and 32 men aged $20-46(M=27.72)$. The differences in skin representation between dermatosis patients and healthy individuals were identified among patients suffering from psoriasis $(n=44$, mean age 37.65), vitiligo ( $n=14$, mean age 31.92 ), juvenile acne $(n=20$, mean age 17.68$)$ and 343 healthy people.

Procedure. Participants were examined individually and in groups. Dermatosis patients were hospitalized in the Department of Dermatology, Sexually Transmitted Diseases and Immunodermatology of the Nicolaus Copernicus University, Collegium Medicum in Bydgoszcz and 20\% of them were outpatients from the "SOPMED" clinic in Sopot (Poland). Healthy people were students from the University of Social Sciences and Humanities and employees from Pomeranian companies in Poland.

\section{RESULTS}

\section{STRUCTURE OF THE MY SKIN QUESTIONNAIRE}

Explanatory factor analysis (EFA) was used to reveal the structure of the MSQ. The final results of EFA with 38 items are presented in Table 1 (for part $\mathrm{AB}$ ) and Table 2 (for part C).

The results in tables show that factor loadings are relatively high. The AB I factor (FACE) measures satisfaction with skin of the head: it is the most visible part of the head and plays an important role in social communication. It includes the skin under the hair,

Table 2

Factor analysis for part C of My Skin questionnaire, $n=343$

\begin{tabular}{lccc}
\hline & Factor 1 & Factor 2 & Factor 3 \\
\hline C I PHYSIO: & & & \\
C2 & .66 & -.33 & .24 \\
C7 & .73 & .10 & .17 \\
C8 & .66 & .20 & .26 \\
C9 & .77 & .10 & -.08
\end{tabular}

C II PSYCHO:

$\begin{array}{lrrr}\mathrm{C} 3 & .08 & .74 & .14 \\ \mathrm{C} 5 & .06 & .75 & .17\end{array}$

\section{III HEALTH}

\begin{tabular}{lrrr}
$\mathrm{C} 4$ & .28 & .03 & .74 \\
$\mathrm{C} 6$ & .13 & .23 & .60 \\
$\mathrm{C} 10$ & .20 & .05 & .76 \\
$\mathrm{C} 1$ & -.09 & .18 & .78 \\
\hline
\end{tabular}


forehead, eyes and nose. Cronbach's $\alpha$ coefficient for this subscale was .80 .

The $\mathrm{AB}$ II factor (UPPER) measures satisfaction with the skin of upper parts of the body, namely those that are occasionally visible: cheeks, lips, chin, ears, neck, back, cleavage, chest/breasts, shoulders, elbows, and hands. These are the parts of the upper body which are visible or seasonally visible for others. Cronbach's $\alpha$ coefficient for this subscale was .89 .

The AB III factor (LOWER) assesses satisfaction with the skin of lower parts of the body (from waist to feet), that is parts that are mostly hidden from, but also occasionally exposed to, others. It includes contentment with the skin of the stomach, genitals, thighs, lower legs, knees, feet, and heels. Cronbach's $\alpha$ coefficient for this subscale was 87 .

AB IV factor related to satisfaction with other aspects of skin (ASPECTS): color, smell, structure of the skin, and the appearance/condition of hair, fingernails, and toenails. Cronbach's $\alpha$ coefficient for this subscale was .84 . For all the AB scales, reliability had a value of around .95 .

In part $A B$, participants should indicate how much they like or dislike a part or aspect of their skin using a Likert scale from 1 to 5 . The higher the score a person obtains, the higher the level of satisfaction in every subscale he/she declares.

Part C of the MSQ reflects the knowledge and awareness of skin functions, and contains three subscales (ten items).
The C I subscale (PHYSIO) assesses awareness or knowledge of the skin's physiological functions: its reactivity to external stimuli, protection against excessive dehydration and irritation, protection against external hazards, and its regeneration ability. The C II subscale measures one's awareness of psycho-sociological functions of the skin as related to personal identity: that the skin is a social border dividing individuals from one another, and also defines an individual from his or her surroundings (PSY$\mathrm{CHO}$ ). The C III subscale measures one's understanding of the relationships between skin and health. Skin may be regarded as an indicator of somatic and mental health (HEALTH). Cronbach's $\alpha$ for part C was relatively good, with a value of .75 .

In part $C$, participants indicate to what extent they agree or disagree with a statement using a Likert scale from 1 to 5 . The higher the score a person achieves, the higher the level of awareness of skin function in a particular subscale he/she reveals.

\section{VALIDITY}

For assessing accuracy aspects of the questionnaire, the MSQ was correlated with three tools: the Body Self Questionnaire, the Body Esteem Scale and the Self-Esteem Scale. Pearson's $r$ values are presented in Table 3. Subscales from part AB strongly correlate with all the three questionnaires. External reliability
My Skin Questionnaire

Table 3

Correlations between My Skin questionnaire and Body Self Questionnaire, Body Esteem Scale and Self-Esteem Scale

\begin{tabular}{|c|c|c|c|c|c|c|c|}
\hline & $\mathrm{AB} 1$ & AB2 & AB3 & $\mathrm{AB} 4$ & $\mathrm{C} 1$ & $\mathrm{C} 2$ & $\mathrm{C} 3$ \\
\hline \multicolumn{8}{|l|}{ Body Self (BSQ), $n=73$ (females only) } \\
\hline 1. Acceptance of body & $.37^{* *}$ & $.53^{* *}$ & $.51^{* *}$ & $.53^{* *}$ & -.01 & $.32^{* *}$ & -.04 \\
\hline 2. Disclosure of femininity & .22 & $.40^{* *}$ & $.33^{* *}$ & $.38^{* *}$ & -.04 & .16 & .05 \\
\hline 3. Experience of intimacy & $.29^{*}$ & $.47^{* *}$ & $.50^{* *}$ & $.54^{* *}$ & -.11 & .17 & -.04 \\
\hline 4. Relations towards eating and weight & $.34^{* *}$ & $.44^{* *}$ & $.47^{* *}$ & $.39^{* *}$ & -.11 & $.28^{*}$ & -.07 \\
\hline \multicolumn{8}{|l|}{ Body Esteem (BES): } \\
\hline \multicolumn{8}{|l|}{ Males, $n=32$} \\
\hline 1. Physical Attractiveness & $.97^{* *}$ & $.84^{* *}$ & $.86^{* *}$ & $.78^{* *}$ & $-.46^{* *}$ & .14 & .25 \\
\hline 2. Upper Body Strength & $.80^{* *}$ & $.67^{* *}$ & $.67^{* *}$ & $.61^{* *}$ & $-.45^{* *}$ & -.02 & .34 \\
\hline 3. Physical Condition & $.87^{* *}$ & $.74^{* *}$ & $.77^{* *}$ & $.72^{* *}$ & $-.52^{*}$ & .00 & .35 \\
\hline \multicolumn{8}{|l|}{ Females, $n=73$} \\
\hline 1. Sexual Attractiveness & $.52^{*}$ & $.62^{* *}$ & $.64^{* *}$ & $.59^{* *}$ & -.06 & .02 & -.16 \\
\hline 2. Weight Concern & $.29^{*}$ & $.49^{* *}$ & $.56^{* *}$ & $.36^{* *}$ & -.07 & .17 & -.09 \\
\hline 3. Physical Condition & $.26^{*}$ & $.35^{* *}$ & $.54^{* *}$ & $.46^{* *}$ & -.12 & .14 & .00 \\
\hline Self-Esteem (SES) & $.34^{* *}$ & $.33^{* *}$ & $.48^{* *}$ & $.48^{* *}$ & -.07 & .02 & -.12 \\
\hline
\end{tabular}


Table 4

Means and standard deviations of My Skin questionnaire in healthy people and dermatology patients

\begin{tabular}{|c|c|c|c|c|c|}
\hline \multirow{3}{*}{\multicolumn{2}{|c|}{$\begin{array}{l}\text { Scales } \\
\text { and subscales of MSQ }\end{array}$}} & \multicolumn{3}{|c|}{$M(S D)$} & \multirow{3}{*}{$\begin{array}{c}\text { dermatosis } \\
\text { patients } \\
n=84\end{array}$} \\
\hline & & \multicolumn{3}{|c|}{ healthy individuals } & \\
\hline & & \multirow{2}{*}{$\begin{array}{c}\text { total } \\
n=343 \\
106.97(18.89)\end{array}$} & \multirow{2}{*}{$\begin{array}{c}\text { females } \\
n=198 \\
106.72(18.75)\end{array}$} & \multirow{2}{*}{$\begin{array}{c}\text { males } \\
n=145 \\
107.55(19.27)\end{array}$} & \\
\hline$A B$ & & & & & $95.47(16.88)$ \\
\hline AB I & FACE & $14.29(3.21)$ & $14.36(3.12)$ & $14.12(3.41)$ & $13.50(3.25)$ \\
\hline$A B I I$ & UPPER & $41.92(7.62)$ & $42.16(7.61)$ & $41.39(7.56)$ & $36.83(7.58)$ \\
\hline AB III & LOWER & $28.58(6.25)$ & $28.25(6.36)$ & $29.34(5.96)$ & $26.06(7.49)$ \\
\hline AB IV & ASPECTS & $22.05(4.68)$ & $21.91(4.65)$ & $22.36(4.76)$ & $19.88(4.31)$ \\
\hline $\mathrm{C}$ & & $35.60(5.56)$ & $36.55(5.69)$ & $34.65(4.75)$ & $38.07(4.97)$ \\
\hline $\mathrm{Cl}$ & PHYSIO & $15.94(2.52)$ & $16.11(2.69)$ & $15.57(2.03)$ & $15.37(2.28)$ \\
\hline C II & PSYCHO & $5.76(1.73)$ & $5.82(1.85)$ & $5.63(1.40)$ & $6.11(2.04)$ \\
\hline C III & HEALTH & $13.91(3.18)$ & $14.30(3.07)$ & $13.01(3.25)$ & $16.07(2.32)$ \\
\hline
\end{tabular}

for part $A B$ is very good. Part $C$ of the MSQ does not correlate with self-esteem. The correlations between skin awareness and body self are weak or none. A similar situation was found for body esteem. There are weak correlations between part $\mathrm{C} 1$ and body esteem but only in females.

\section{NORMATIVE DATA}

Normative data were established in a sample of healthy people $(n=343)$, separately for males and females. Basic statistics for the MSQ, with means

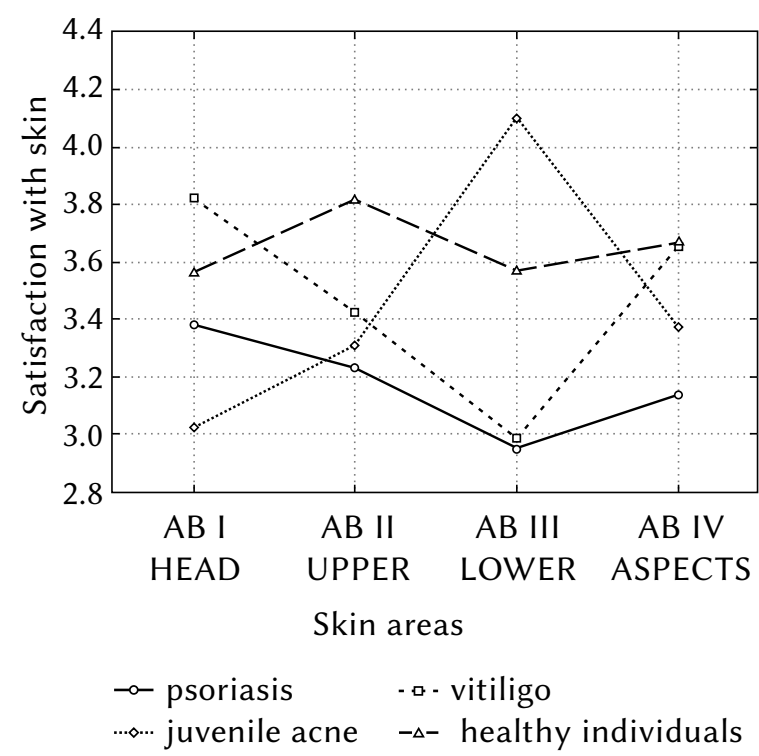

Figure 1. Skin satisfaction in psoriasis $(n=42)$, vitiligo $(n=14)$, acne $(n=20)$ compared to healthy individuals $(n=343)$. Preliminary report. and standard deviations, are presented in Table 4. Additionally, the preliminary means and standard deviations for dermatology patients ( $n=84$; psoriasis, vitiligo, and juvenile acne) were presented for comparison, as previous research has revealed that dermatology patients differ from healthy people in terms of their skin representation. A sample of dermatological patients was partly recruited from the Department of Dermatology, Medical College of Nicolaus Copernicus University in Bydgoszcz, and the Medical University of Gdansk, as well as from an out-patient "SOPMED" clinic in Sopot, Poland.

To verify the differences between dermatosis patients, two separate repeated ANOVA/MANOVA analyses were run in models: 1) 4 group (psoriasis, vitiligo vs. juvenile acne vs. healthy individuals) $\times 4$ satisfaction with skin (HEAD vs. UPPER vs. LOWER vs. ASPECTS) and 2) 4 group (psoriasis, vitiligo vs. juvenile acne vs. healthy individuals) $\times 3$ representation of skin (PHYSIO vs. PSYCHO vs. HEALTH). The first analysis revealed the interaction effect $F(9,1281)=3.09$, $p<.001$ (Figure 1), which indicates the differences between patients in level of satisfaction with skin in various areas of the body. The post hoc LSD test showed that the lowest level of skin satisfaction with lower parts of the body (LOWER) was found in psoriasis and vitiligo patients. Young acne patients compared to healthy people were not satisfied with the facial skin (HEAD). They were also prone to overestimate the condition of the skin of the lower parts of the body.

The second ANOVA/MANOVA analysis revealed the interaction effect $F(6,742)=3.49, p=.006$. Post hoc LSD test analysis showed that there were no significant differences in the extent of awareness of the physiological functions of skin between dermatoses 
and healthy individuals. However, the belief that skin is an important border between the inner and external world was much stronger among dermatological patients (except psoriasis patients) compared to the control group. Psoriasis and acne patients also held a stronger belief of skin being a general health indicator (C III) (Figure 2).

\section{DISCUSSION}

The MSQ presented in this article is a good proposal, in terms of psychometric aspects, for an instrument to allow the grasp and measurement of a theoretical construct of the skin representation. It is intended for adults, and can be used for both examining healthy individuals, in order to perceive differences in the level of skin satisfaction for various parts of the body, and to determine the level of awareness of its role in a person's life (e.g. race, gender, age differences, etc.). The questionnaire, however, seems to be especially useful to measure skin representation among people who are particularly focused on what their skin looks like. These groups include dermatology patients, and clients of beauty parlors or esthetic surgery centers. Initial analyses show that dermatology patients are more dissatisfied with their skin of all body parts, and are more aware that their skin reflects their health condition (Kossakowska, Cieścińska, Górska, \& Placek, 2011). Preliminary research seems to be promising, and encourages the use of the questionnaire for various groups of patients suffering from skin-related illnesses. Measuring the skin representation in various clinical groups will allow us to estimate the level of satisfaction and awareness connected with skin, while simultaneously employing measurements of the skin representation to test the effectiveness of various types of medical and therapeutic influences that are aimed at improving the condition and appearance of the skin (cosmetic, medical and plastic surgery treatments). The skin ego could have significant implications not only in terms of self-satisfaction, which is included in the scope of dermatology patients' self-assessments, but could also have connections with aspects of quality of life that depend on health condition (health-related quality of life), such as dealing with skin diseases, or accepting one's skin where it has been seriously damaged. These relationships between the skin representation and the numerous psychological or medical factors must be, however, verified empirically. My Skin questionnaire could subsequently be used, for example, in improving the quality of life in dermatoses.

A very important reason to use the MSQ is that it could be a vital tool to check for psychological, or even psychiatric, influences on people who excessively focus on their skin appearance. For example,

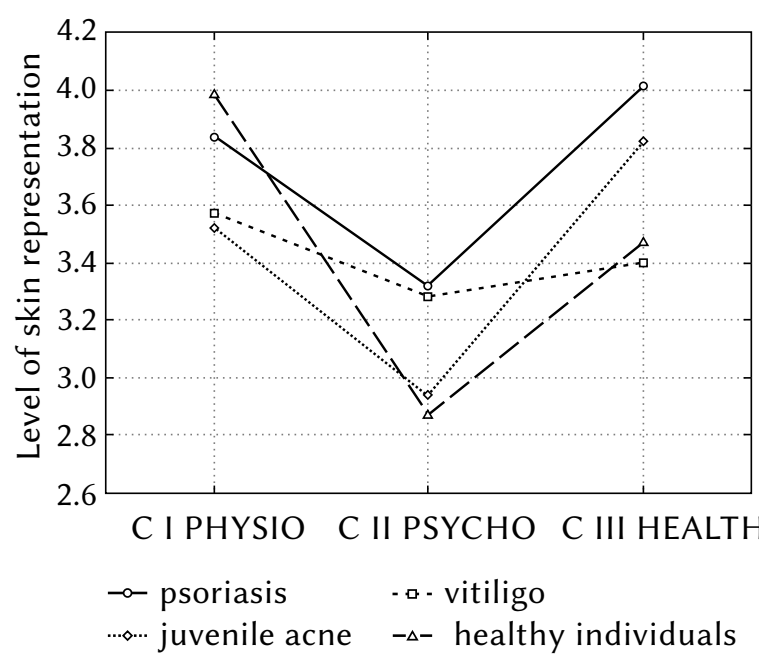

Figure 2. Physiological (PHYSIO), psychological (PSYCHO) and health-related (HEALTH) awareness of skin functions in psoriasis, vitiligo, and juvenile acne compared to healthy individuals.

it could be used for those who demand medical or cosmetic treatments which are harmful to them, i.e. when side effects exceed the benefits of esthetic dermatology interventions. It could also be used to measure the skin representation to assess distortions in skin perception (e.g. body dysmorphic disorder) or compulsions that are focused on the skin.

The questionnaire's psychometric properties are satisfactory. The MSQ is characterized by high reliability of the $\mathrm{AB}$ scale, as well as a good and stable factor structure. Results of a factor analysis and reliability tests for the $\mathrm{C}$ scale also show satisfactory parameters as compared to the scale's general results.

The analysis of criteria accuracy shows that part $\mathrm{AB}$ of the questionnaire correlates well with measures of the body self, body esteem and self-esteem. Assessing the questionnaire's accuracy still requires, however, more research and analysis, because part $\mathrm{C}$ is only moderately correlated with the instruments employed in this research. Therefore, it is necessary to continue empirical verification of the theoretical accuracy of part $\mathrm{C}$ in order to search for correlates, appropriate for that scale, among other psycho-social variables (e.g. negative and positive emotions, life satisfaction, health-related quality of life, etc.). The questionnaire's accuracy will still require further testing, especially with clinical groups, dermatology patients, and clients of esthetic surgery centers and cosmetic parlors. The usefulness of the MSQ seems to be justified and requires additional investigative research on populations all over the world.

\section{ACKNOWLEDGMENTS}

The author wishes to thank the patients and staff of the Department of Dermatology, Medical Col-
My Skin Questionnaire 
lege of Nicolaus Copernicus University in Bydgoszcz, the Medical University of Gdansk, and the "SOPMED" clinic in Sopot (Poland). I would especially like to thank Izabela Gorska, who partially collected the data for this research. This study was supported by the Polish National Science Centre Grant DEC-2011/03/B/HS6/01117 for Dr. Marlena Kossakowska.

Marlena M. Kossakowska, Czanita Cieścińska

\section{References}

American Psychological Association. (1999). Standards for Educational and Psychological Testing. Washington DC: APA.

Anzieu, D. (1989). The Skin Ego. New Haven CT: Yale University Press.

Franzoi, S. L., \& Herzog, M. E. (1986). The Body Esteem Scale: A convergent and discriminant validity study. Journal of Personality Assessment, 50, 24-31.

Franzoi, S. L., \& Shields, S. A. (1984). The Body Esteem Scale: Multidimensional structure and sex differences in a college population. Journal of Personality Assessment, 48, 173-178.

Ginsburg, I. H., \& Link, B. G. (1989). Feelings of stigmatization in patients with psoriasis. Journal of the American Academy of Dermatology, 20, 53-63.

Gupta, M. A. (2005). Psychiatric comorbidity in dermatologic disorders. In C. Walker \& L. Papadopoulos (eds.), Psychodermatology. The psychological impact of skin disorders (pp. 29-43). Cambridge: Cambridge University Press.

Kent, G. (1999). Correlates of perceived stigma in vitiligo. Psychology \& Health, 14, 241-251.

Kent, G. (2005). Stigmatisation and skin conditions. In C. Walker \& L. Papadopoulos (eds.), Psychodermatology. The psychological impact of skin disorders (pp. 44-56). Cambridge: Cambridge University Press.

Kimball, A. B., Jacobson, C., Weiss, S., Vreeland, M. G., \& Wu, Y. (2005). The psychosocial burden of psoriasis. American Journal of Clinical Dermatology, 6, 383-392.

Kossakowska, M. (2011). Prezentacja kwestionariusza "Moja Skóra" do mierzenia subiektywnej reprezentacji poznawczo-emocjonalnej skóry [Presentation of My Skin questionnaire for assessing the subjective emotional-cognitive representation of skin]. Dermatologia Estetyczna, 13, 106-112.

Kossakowska, M., Cieścińska, C., Górska, I., \& Placek, W. J. (2011). Skin-Ego as the emotional and cognitive representation of skin among patients with dermatoses. Paper presented at the $14^{\text {th }}$ Congress of the European Society for Dermatology and Psychiatry, Zaragoza, Spain, March 17-19, 2011.

Lipowska, M., \& Lipowski, M. (2013). Polish normalization of the Body Esteem Scale. Health Psychology Report, 1, 72-81. doi: 10.5114/hpr.2013.40471
Magin, P., Adams, J., Heading, G., Pond, D., \& Smith, W. (2009). The psychological sequelae of psoriasis: Results of a qualitative study. Psychology, Health \& Medicine, 14, 150-161.

Mirucka, B. (2005). Kwestionariusz Ja Cielesnego (Skala J-C) [Body Self Questionnaire (J-C Scale)]. Przegląd Psychologiczny, 48, 313-329.

Rosenberg, M. (1965). Society and the adolescent self-image. Princeton: Princeton University Press.

Rosenberg, M. (1979). Conceiving the self. New York: Basic. 


\section{APPENDIX}

\section{My Skin}

(Marlena M. Kossakowska, Ph.D.)

First name and last name:

Age:

Education:

Date:

The purpose of this questionnaire is to examine how people perceive their skin in different areas of their body, how they feel about their skin, and what they know about it. The My Skin questionnaire is made up of 2 parts: $A B$ and $C$. Part $A B$ measures your perception of selected areas of the skin and its properties. Part $C$ focuses on your perception of your skin as a whole. There are different instructions for each part of the questionnaire. Please read the instructions carefully.

Part $\mathrm{AB}$

Please indicate how much you like your skin in different areas of your body on a scale of 1 to 5 .

Please circle one answer that describes how much you like your skin.

$$
\begin{aligned}
& 1=I \text { don't like it at all } \\
& 2=I \text { don't like it } \\
& 3=I \text { have no idea (it's hard to say) } \\
& 4=I \text { like it } \\
& 5=I \text { like it very much }
\end{aligned}
$$

\begin{tabular}{|c|c|c|c|c|c|}
\hline AB1. Head/scalp & 1 & 2 & 3 & 4 & 5 \\
\hline AB2. Forehead & 1 & 2 & 3 & 4 & 5 \\
\hline AB3. Eyes & 1 & 2 & 3 & 4 & 5 \\
\hline AB4. Nose & 1 & 2 & 3 & 4 & 5 \\
\hline AB5. Cheeks & 1 & 2 & 3 & 4 & 5 \\
\hline AB6. Lips & 1 & 2 & 3 & 4 & 5 \\
\hline AB7. Chin & 1 & 2 & 3 & 4 & 5 \\
\hline AB8. Ears & 1 & 2 & 3 & 4 & 5 \\
\hline AB9. Neck & 1 & 2 & 3 & 4 & 5 \\
\hline AB10. Back & 1 & 2 & 3 & 4 & 5 \\
\hline AB11. Cleavage & 1 & 2 & 3 & 4 & 5 \\
\hline AB12. Chest/breasts & 1 & 2 & 3 & 4 & 5 \\
\hline AB13. Shoulders & 1 & 2 & 3 & 4 & 5 \\
\hline AB14. Elbows & 1 & 2 & 3 & 4 & 5 \\
\hline AB15. Hands & 1 & 2 & 3 & 4 & 5 \\
\hline AB16. Stomach & 1 & 2 & 3 & 4 & 5 \\
\hline AB17. Genitals & 1 & 2 & 3 & 4 & 5 \\
\hline AB18. Thighs & 1 & 2 & 3 & 4 & 5 \\
\hline AB19. Lower legs & 1 & 2 & 3 & 4 & 5 \\
\hline AB20. Knees & 1 & 2 & 3 & 4 & 5 \\
\hline AB21. Feet & 1 & 2 & 3 & 4 & 5 \\
\hline AB22. Heels & 1 & 2 & 3 & 4 & 5 \\
\hline
\end{tabular}

Indicate how much you like your skin on/around your... 
Please indicate how much you like the characteristics of your skin on the following scale:

$1=I$ don't like it at all

$2=$ I don't like it

$3=1$ have no idea (it's hard to say)

$4=1$ like it

$5=I$ like it very much

Indicate how much you like...

Marlena M. Kossakowska,

Czanita

Cieścińska

\begin{tabular}{|c|c|c|c|c|c|}
\hline AB23. The color of your skin & 1 & 2 & 3 & 4 & 5 \\
\hline AB24. The smell of your skin & 1 & 2 & 3 & 4 & 5 \\
\hline AB25. The structure of your skin & 1 & 2 & 3 & 4 & 5 \\
\hline AB26. The appearance and condition of your hair & 1 & 2 & 3 & 4 & 5 \\
\hline AB27. Your fingernails & 1 & 2 & 3 & 4 & 5 \\
\hline AB28. Your toenails & 1 & 2 & 3 & 4 & 5 \\
\hline
\end{tabular}

Part C

Please indicate how much you agree or disagree with the statements listed below. Please circle the answer that best describes how much you agree or disagree.

$$
\begin{aligned}
& 1=\text { strongly disagree } \\
& 2=\text { disagree } \\
& 3=\text { neutral (neither agree nor disagree) } \\
& 4=\text { agree } \\
& 5=\text { strongly agree }
\end{aligned}
$$

\begin{tabular}{|c|c|c|c|c|c|}
\hline C1. I feel sick when there is something wrong with my skin. & 1 & 2 & 3 & 4 & 5 \\
\hline C2. My skin reacts to the environment and other external sources. & 1 & 2 & 3 & 4 & 5 \\
\hline C3. I am distinguishable from people because of my skin. & 1 & 2 & 3 & 4 & 5 \\
\hline C4. The appearance of my skin affects how I feel. & 1 & 2 & 3 & 4 & 5 \\
\hline C5. My skin insulates me from the rest of the world. & 1 & 2 & 3 & 4 & 5 \\
\hline C6. Having healthy skin makes me feel socially acceptable. & 1 & 2 & 3 & 4 & 5 \\
\hline C7. My skin protects me from excessive dehydration and hydration. & 1 & 2 & 3 & 4 & 5 \\
\hline C8. My skin is a shield protecting me from the dangers of the world. & 1 & 2 & 3 & 4 & 5 \\
\hline C9. My skin regenerates over and over again. & 1 & 2 & 3 & 4 & 5 \\
\hline C10. My skin reflects the state of my health. & 1 & 2 & 3 & 4 & 5 \\
\hline
\end{tabular}

